\title{
Análisis de la población de células T reguladoras Foxp3 en el modelo murino de amibiasis intestinal
}

\author{
Claudia Andrea Cruz B' , Mauricio Sarrazola S', Juan Pedro Laclette S² \\ 1. Universidad de Pamplona. Facultad de Ciencias de la Salud, Departamento de Medicina. \\ 2. Universidad Nacional Autónoma de México. \\ Instituto de Investigaciones Biomédicas, Departamento de Inmunología.
}

Correspondencia: laclette@correo.biomedicas.unam.mx

Recibido: 02-05-2011 / Aceptado: 05-04-2010

\begin{abstract}
Resumen
La amibiasis es una infección causada por el parásito E. histolytica, que tiene alta incidencia en países en vía de desarrollo. En los últimos años se ha estudiado el papel de las células Treg en varias enfermedades parasitarias, que pueden llegar a tener efectos benéficos o perjudiciales. El objetivo central de este proyecto fue investigar la participación de las células Treg en un fenómeno de inmunosupresión observada previamente en un modelo murino de amibiasis intestinal. Para ello se estudió el comportamiento poblacional de las células Treg a diferentes periodos post-infección. Sin embargo, los resultados obtenidos perecen sugerir que las células Treg no participan en este fenómeno de inmunosupresión.
\end{abstract}

Palabras clave: amibiasis, células Treg, Entamoeba histolytica, esplenocitos trofozoítos.

\section{Abstract \\ Analysis of the population of Foxp3 regulatory T cells in the murine model of intestinal amoebiasis}

Amebiasis is a parasitic infection caused by $E$. histolytica, its incidence is higher in developing countries. Recently we have studied the role of Treg cells in several parasitic diseases, which can have beneficial or harmful. The goal of this project was to investigate the role of Treg cells in an immunosuppressive phenomenon previously observed on mouse model of intestinal amoebiasis. Thus, the behavior of Treg population cells was studied at different periods post-infection. However, the results suggest that Treg cells are not involved in this phenomenon of immunosuppression.

Keywords: amebiasis, Treg cells, Entamoeba histolytica, splenocytes trophozoites. 


\section{Introducción}

El parásito protozoario Entamoeba histolytica es el agente causante de la disentería amibiana y el absceso hepático amibiano, que genera más de 40 millones de casos de diarrea en el mundo, y junto con el absceso hepático son responsables de 50.000 muertes anuales, siendo la tercera causa de muerte por parásitos (1). Aunque la infección aguda con $E$. histolytica induce una respuesta inmune en el hospedero, en muchas ocasiones la invasión de tejido por este parásito está asociada con supresión de la inmunidad mediada por células $\mathrm{T}$ (2).

La mayoría de los estudios sobre inmunidad contra la amibiasis se han realizado en modelos experimentales en roedores. En dichos modelos también se ha demostrado que la anergia de células T, en términos de capacidad proliferativa, acompaña la invasión del hígado y la infección intestinal por amibas. Estudios realizados para evaluar la respuesta inmune en un modelo de amibiasis intestinal en ratones $\mathrm{C} 3 \mathrm{H} / \mathrm{HeJ}$, el mejor conocido hasta ahora y el único susceptible a la infección, demostró que la inoculación de trofozoítos en el ciego de los animales y el establecimiento de la infección, cursó con una depresión cíclica de la íntesis de ADN cuando los linfocitos de bazo fueron estimulados con Concanavalina A (mitógeno de células T), PWM (de células T y B) y extracto crudo de amiba (3). La supresión se observó en ciclos de 10 a 20 días durante los dos meses de seguimiento y se asoció con un defecto en la transducción de señales en los linfocitos. El mismo fenómeno se observó cuando se evaluó la respuesta de hipersensibilidad de tipo-retardada en dichos ratones infectados (4).

Es reciente el interés por las células $T$ reguladoras (Treg), antes llamadas células $\mathrm{T}$ supresoras. Los primeros estudios fueron realizados por Sakaguchi y colaboradores, y observaron que las células Treg eran esenciales en la homeostasis del sistema inmune. Las células $\mathrm{T}$ reguladoras comprende de $5-10 \%$ de las células $\mathrm{CD} 4^{+}$periféricas (5-7) y su función principal es controlar la respuesta inmune por medio de la supresión de la proliferación, evitando así el daño colateral del tejido por la misma respuesta.

La inducción de la respuesta regulatoria es una estrategia común usada por el parásito y normalmente se asocia con la terminación de la respuesta inmune efectora del huésped (8). En recientes estudios se ha observado que las células Treg son perjudiciales en Malaria donde éstas regulan la respuesta inmune efectora permitiendo la expansión incontrolada del parásito, induciendo la muerte del huésped (9). Por otro lado, las células Treg pueden actuar como benéficas en otras parasitosis como los causantes de las enfermedades de Esquistosomiasis y Leishmaniasis (Leishmania amazonensis), debido a que estas células controlan la inmunopatología a través de la producción de la IL-10. (10-13).

El objetivo central de este proyecto fue investigar la participación de las células Treg en un fenómeno de inmunosupresión observado previamente en un modelo murino de amibiasis intestinal. Para ello, se estudió el comportamiento poblacional de las células Treg a diferentes periodos post-infección, comparado con el de células obtenidas de animales no infectados.

\section{Materiales y métodos}

Cultivo y cosecha de trofozoítos de Entamoeba bistolytica. Trofozoítos axénicos de la cepa HM1:IMSS recién obtenidos de hígado de hámster para incrementar su virulencia. Se cultivaron a $37^{\circ} \mathrm{C}$ en TYI-33 suplementado con $10 \%$ de suero bovino adulto, $100 \mathrm{U} / \mathrm{ml}$ de penicilina y $100 \mathrm{ug} / \mathrm{mL}$ de sulfato de estreptomicina.

Preparación de antígeno amibiano total. Los trofozoítos cultivados se lavaron tres veces con PBS $1 \mathrm{X}$ en condiciones estériles. El pellet resultante, de la última centrifugación, se subdividió en tubos de $1,5 \mathrm{~mL}$ que se mantuvieron a $-20^{\circ} \mathrm{C}$ hasta su uso.

El modelo murino de amibiasis intestinal. Se utilizaron ratones singénicos $\mathrm{C} 3 \mathrm{H} / \mathrm{HEJ}$, hembras de 4-6 semanas de edad, obtenidos de la colonia mantenida en el Instituto de Investigaciones Biomédicas de la Universidad Nacional Autónoma de México.

Inoculación intracecal de trofozoítos de Entamoeba histolytica. El diseño experimental se basó en 9 grupos, cada uno de 6 ratones, de los cuales 4 fueron infectados con trofozoítos y 2 inyectados con PBS 1X (controles). Los ratones de cada grupo se mantuvieron en jaulas separadas; el sacrificio se llevó a cabo a los 5, 10, 15, 20, 25, 30, 40, 50 y 60 días post-infección. 
Extracción de células de bazo, de ganglios mesentéricos y de placas de peyer. Las células extraídas se lavaron tres veces con medio de cultivo y se determinó su índice de viabilidad en una cámara de Newbauer utilizando azul de tripano, para ajustar la densidad a $5 \times 10^{5}$ células en $100 \mu \mathrm{L}$ de medio.

Marcación de los linfocitos con CFDASE (carboxifluo-ceindiacetato). Se tomaron $2 \times 10^{6}$ células de cada órgano y se lavaron dos veces con PBS, se resuspendieron en $500 \mu \mathrm{L}$ de PBS para luego agregar $500 \mu \mathrm{L}$ de una solución $2 \mu \mathrm{M}$ de CFDASE (INVITROGEN Cell Trace CFSE Cell proliferation kit for flow citometry C34554), lo que resultó en una dilución final de $1 \mu \mathrm{M}$.

Ensayo de proliferación celular. Para los ensayos de proliferación celular se utilizaron placas para ELISA de 96 pozos, se colocaron en cada pozo $5 \times 10^{5}$ células fueron estimuladas con $1 \mu \mathrm{g}$ concanavalina A (SIGMA C-2010) o con $50 \mu \mathrm{g}$ de antígeno amibiano total. Otras células no fueron estimuladas y se utilizaron como control. Todos los ensayos se incubaron a $37^{\circ} \mathrm{C}$ en una atmósfera con $5 \%$ de $\mathrm{CO}_{2}$ durante 72 horas.
Marcaje de las células treg. Se utilizó un kit para identificar células Treg basado en la detección de los marcadores celulares CD4, CD25 y Foxp3 (e-Bioscience, Mouse Regulatory T cell Staining Kit \# 3, Cat. 88-8115). Para ello, se tomaron $3 \times 10^{6}$ células de cada órgano: células de bazo, placas de Peyer y ganglios mesentéricos, se incubaron con anticuerpos marcados con distintos fluorocromos: IgG anti-CD4 FITC (Cat. 11- 0042) dilución 1/100 y IgG anti-CD25 PE (Cat.12-0251) dilución 1/200 y IgG anti-Foxp3 PECy5 (Cat.15-5773) dilución 1/50. Se almacenaron a $4^{\circ} \mathrm{C}$ hasta ser leídas en el citofluorómetro, Figura 1 .

Citofluorometría. El citófluorómetro que se utilizó fue un FACScalibur de Becton Dickinson. Los datos obtenidos se analizaron con el software Winmdi 2.9, se tuvo en cuenta el porcentaje total de células Foxp $3^{+}$, células $\mathrm{CD} 4^{+} \mathrm{CD} 25^{+}$Foxp $3^{+}$ y células $\mathrm{CD} 4^{+} \mathrm{CD} 25^{-}{ }^{-}$oxp $3^{+}$presentes en los diferentes órganos linfoides secundarios, y el índice de proliferación de los ratones en los diferentes tiempos post-infección, en comparación con los grupos de ratones no infectados,
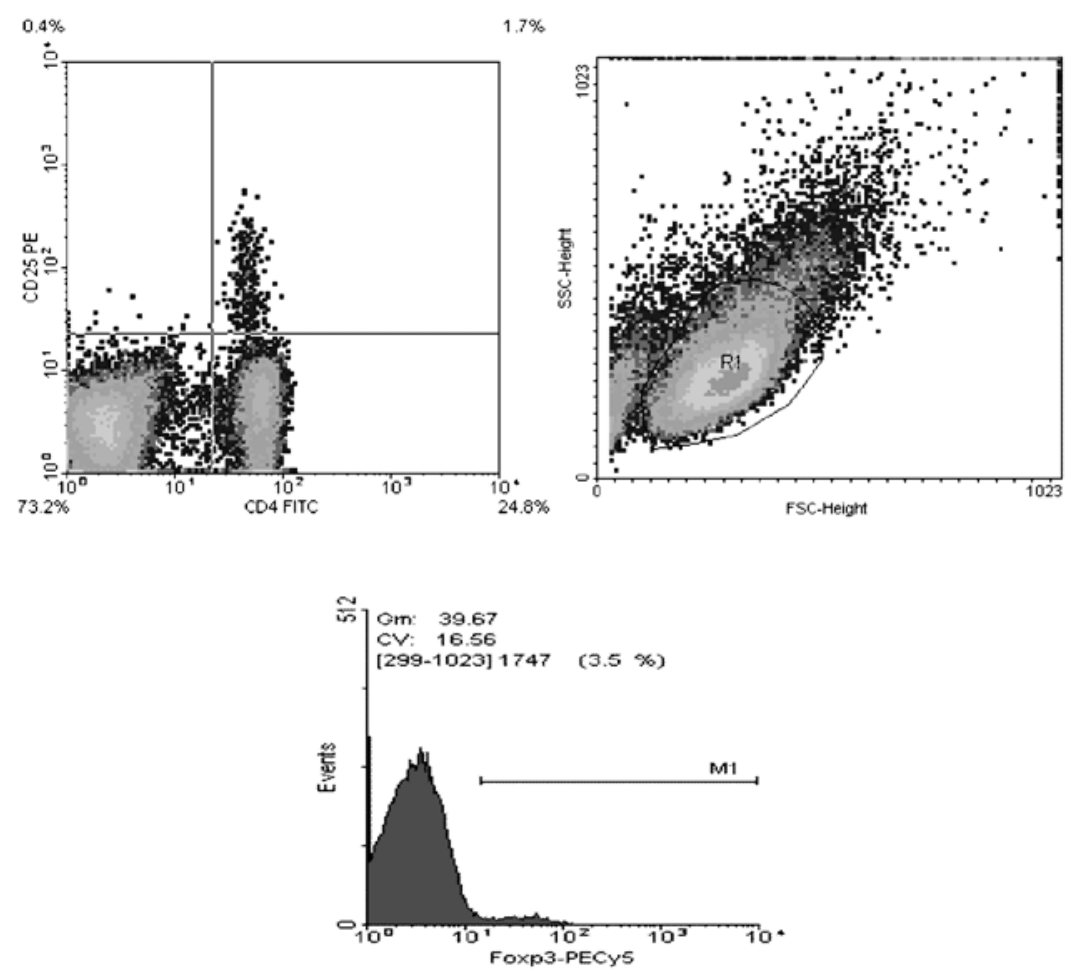

Figura 1. Análisis de poblaciones de células Treg. Nota: R1 es la población total de linfocitos, a partir de ésta región se realizó otro dot plot y se ubicó R2 que son los linfocitos que son dobles positivas para CD4 y CD25 y R3 los linfocitos que son sólo CD4. A partir de estas regiones se realizaron histogramas para saber qué porcentaje de estas células eran Foxp3. 


\section{Resultados}

Implementación del modelo murino de amibiasis intestinal. Los grupos de ratones singénicos $\mathrm{C} 3 \mathrm{H} / \mathrm{HeJ}$, hembras de 4-6 semanas de edad, que fueron inoculados intracecalmente con $1 \times 10^{6}$ trofozoítos de E. histolytica mostraron una supervivencia $>95 \%$ en todos los tiempos experimentales: $5,10,15,20,25,30,40,50$ y 60 días postinfección. El diagnóstico de amibiasis intestinal se llevó a cabo por observaciones macroscópicas de los ciegos y basados en estudios anteriores que demuestran que más del $90 \%$ de los ratones suelen infectarse presentando una colitis activa, a diferencia de los ratones no infectados.

\section{Ensayos de proliferación linfocitaria en ratones} infectados y no infectados. Para realizar los ensayos de proliferación se decidió probar el método de captación de un compuesto fluorescente (CFDASE: carboxifluoresceindiacetato), que se evalúa por medio de un citofluorómetro. El principio del método se basa en la captación celular del colorante por difusión pasiva, el cual al llegar al citoplasma de las células activas se convierte en un emisor de fluorescencia. Incluso, es posible monitorear la división celular, puesto que cuando se dividen las células también se divide la cantidad del fluorocromo. Se realizaron estimulaciones por concanavalina $\mathrm{A}$ (ConA) y por antígeno total amibiano. La ConA es un mitógeno de células $\mathrm{T}$ y se utiliza como control para evaluar la proliferación inespecífica de los linfocitos. En contraste, la estimulación por antígeno amibiano induce la proliferación de las poblaciones celulares que reconocen específicamente a los antígenos, y por consecuencia, es de una magnitud menor.

Como se muestra en la figura 2, las células de bazo provenientes de ratones infectados, proliferaron ante la estimulación por ConA (figura 2a), aproximadamente igual al de células de los ratones no infectados. Resultados similares se obtuvieron con células de ganglios mesentéricos (figura 2b) y placas de Peyer (figura 2c), provenientes de ratones infectados y no infectados. En contraste, las células de bazo de los ratones infectados respondieron más activamente al estímulo del antígeno amibiano en los tiempos cortos del cultivo (antes de los 20 días postinfección) (figura 2d). Sin embargo, no se observaron diferencias significativas en la respuesta proliferativa al antígeno amibiano, entre las células de ganglios mesentéricos (figura 2e) y de placas de Peyer (figura 2f) en ratones infectados y no infectados, a pesar de que en el caso de las células de placas de Peyer se observó una diferencia considerable al día 10 de postinfección.

Análisis de las poblaciones de células treg en ratones infectados y no infectados. $\mathrm{El}$ siguiente paso consistió en determinar la cantidad de células Treg a lo largo de la infección. Para ello, se marcaron las células de los ratones infectados y no infectados con anticuerpos fluorescentes que reconocen marcadores característicos de células Treg (CD4, CD25 y Foxp3). Una vez marcadas las células de bazo, ganglio mesentérico y placa de Peyer, se analizaron las poblaciones en un citófluorómetro. Se tomó en cuenta la cantidad de células identificadas en una determinada región (\% GATE), así como la intensidad media de fluorescencia ( $G$ mean) que se obtiene por el marcaje de cada molécula de superficie $\left(\mathrm{CD}^{+}, \mathrm{CD} 25^{+}\right.$y Foxp $\left.3^{+}\right)$. Este último parámetro permite conocer el nivel de expresión de los marcadores por célula, y de esta manera, conocer el comportamiento de la población de las células Treg. Se analizaron las siguientes poblaciones: (1). Foxp $3^{+}$, (2). $\mathrm{CD}^{+} \mathrm{CD} 25^{+} \mathrm{Foxp}^{+}$y (3). $\mathrm{CD}^{+}{ }^{+}$Foxp $3^{+}$.

Como se describe en los siguientes encabezados, los resultados no mostraron diferencias significativas en las poblaciones de células Treg entre ratones infectados y no infectados, con la excepción de la población $\mathrm{CD}^{+}{ }^{+} \mathrm{Foxp}^{+}$proveniente de ganglios mesentéricos de ratones infectados, que estaban aumentados en los días 10 y 25 en comparación con los ratones no infectados. Todos los datos fueron sometidos a un análisis estadístico de varianza y prueba Post Hoc para determinar su significancia.

\section{Células Treg CD4 ${ }^{+}$Foxp3 ${ }^{+}$evaluadas como} porcentaje de la población total (\%GATE). La evaluación cuantitativa de las células $\mathrm{CD} 4^{+}$Foxp $3^{+}$ nuevamente mostró variaciones sincrónicas (por ejemplo en el día 10) entre las células de bazo (Figura 3a), ganglio mesentérico (Figura 3b) y placa de Peyer 
Bazo (Con A)

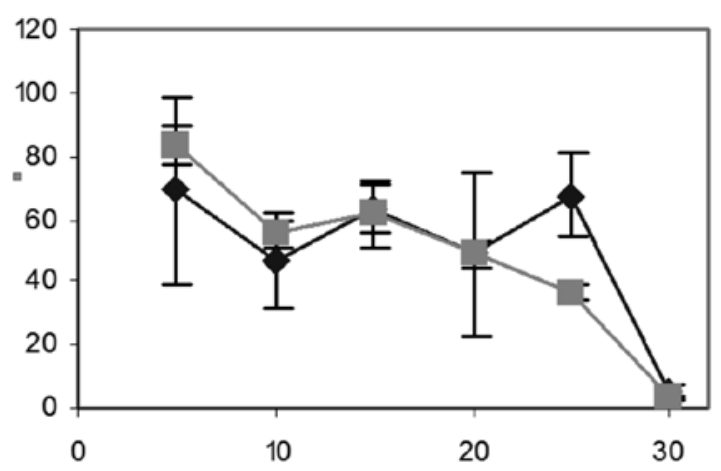

Placas de Peyer (Con A)

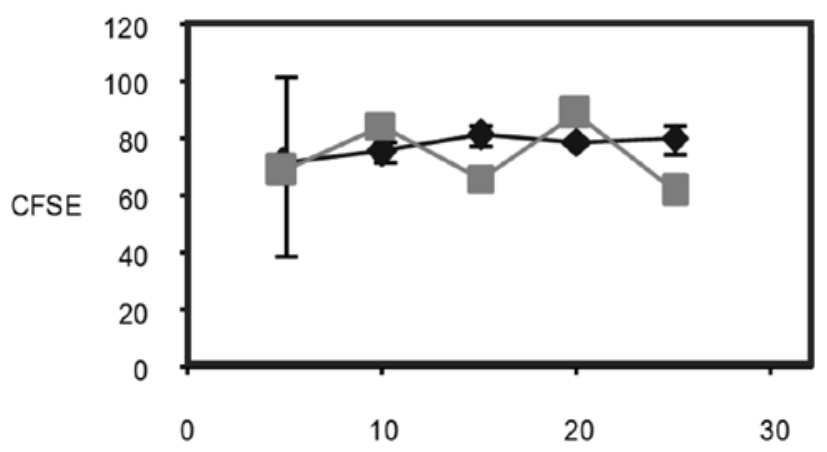

Ganglios mesentéricos (Con A)

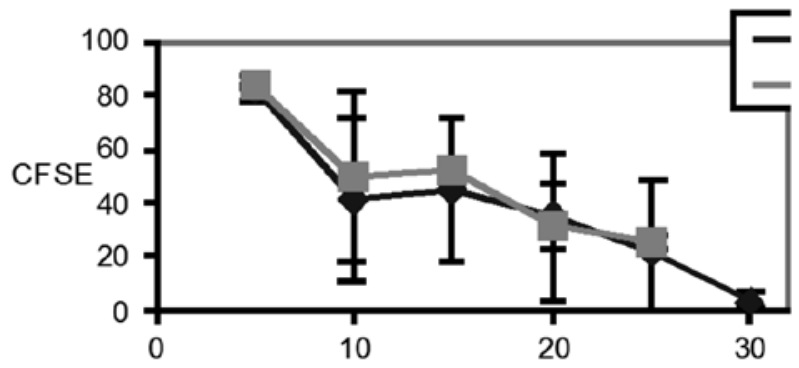

$\operatorname{Bazo}(\mathrm{Ag})$

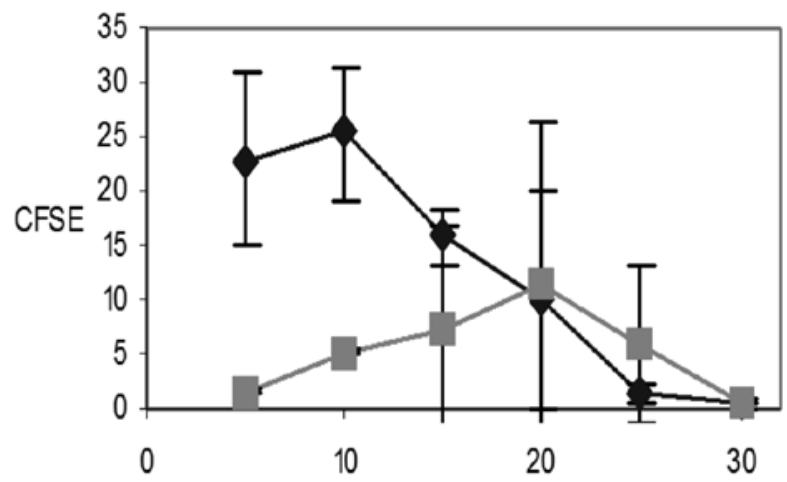

Placas de Peyer (Ag)

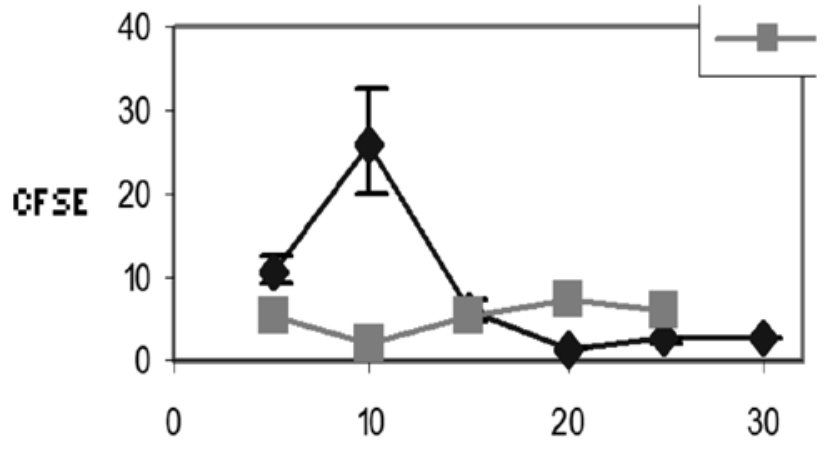

Ganglios mesentéricos ( $\mathrm{Ag})$

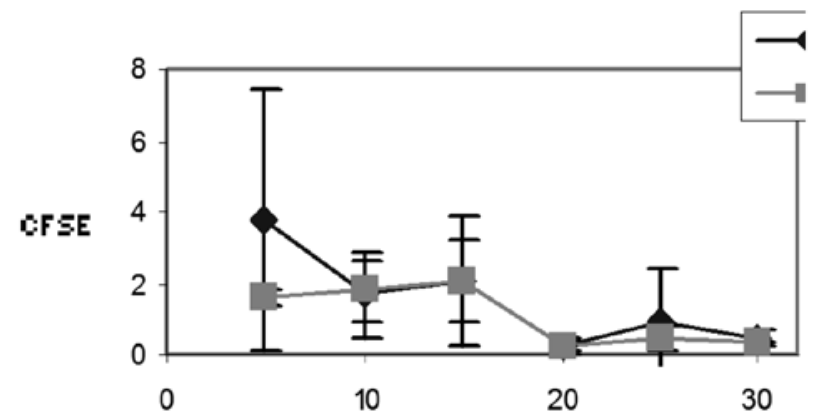

Figura 2. Análisis de la proliferación celular de diferentes órganos linfoides de ratones infectados y no infectados con E. histolytica

(Figura 3c), provenientes de ratones infectados y no infectados. Los resultados de los ratones infectados se desarrollan en el tiempo muy cercanamente a los de ratones no infectados, además las desviaciones estándar son muy altas.

Población de células Treg CD4 ${ }^{+}$Foxp $3^{+}$evaluadas como la intensidad media de fluorescencia (G mean). Por último, las desviaciones estándar entre las células de ratones infectados y no infectados, medidas como promedio de la intensidad de fluorescencia de las células $\mathrm{CD}^{+}{ }^{+}$Foxp $3^{+}$impidieron discernir variaciones entre las células provenientes obtenidas de bazo (Figura 4a), ganglio mesentérico (Figura 4b) y placa de Peyer (Figura 4c). Al igual que en los casos anteriores, aunque se observaron oscilaciones en los días $5,10,15,40$ y 60, estas ocurren simultáneamente para los ratones infectados y los no infectados. 


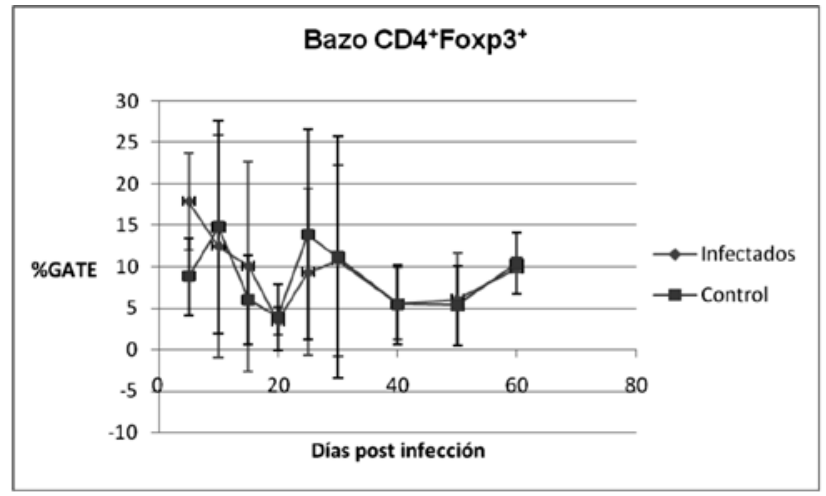

(a)

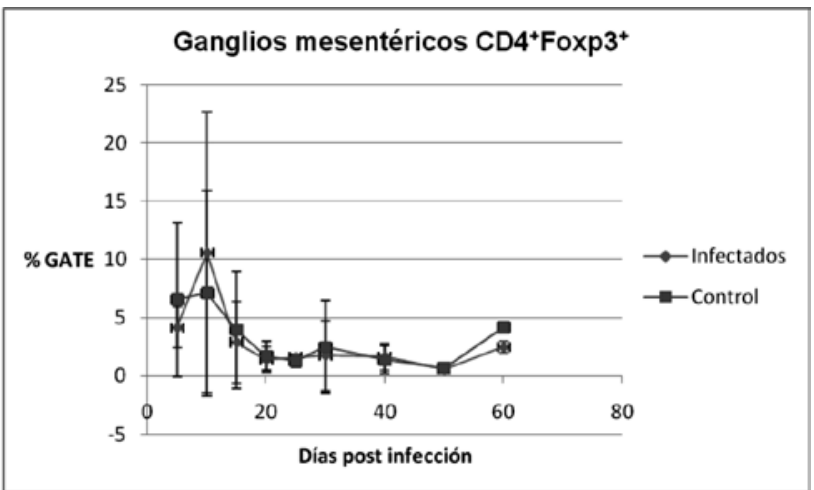

(b)

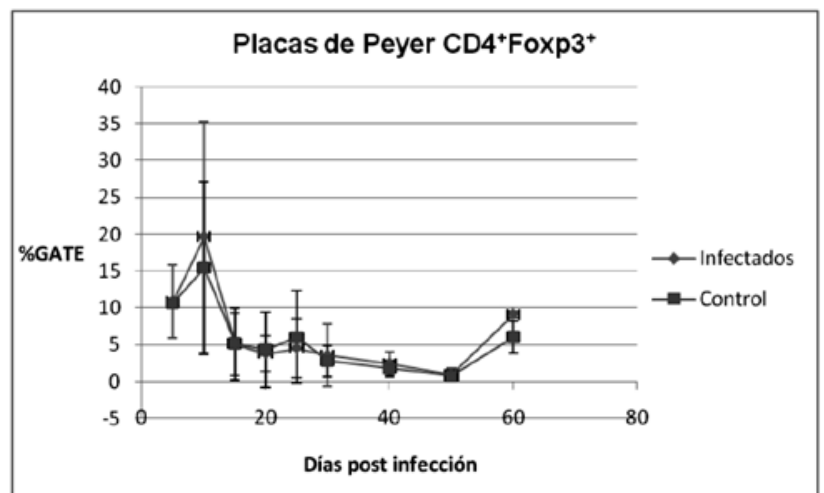

(c)

Figura 3. Porcentaje GATE de linfocitos $\mathrm{CD} 4^{+} \mathrm{Foxp} 3^{+}$

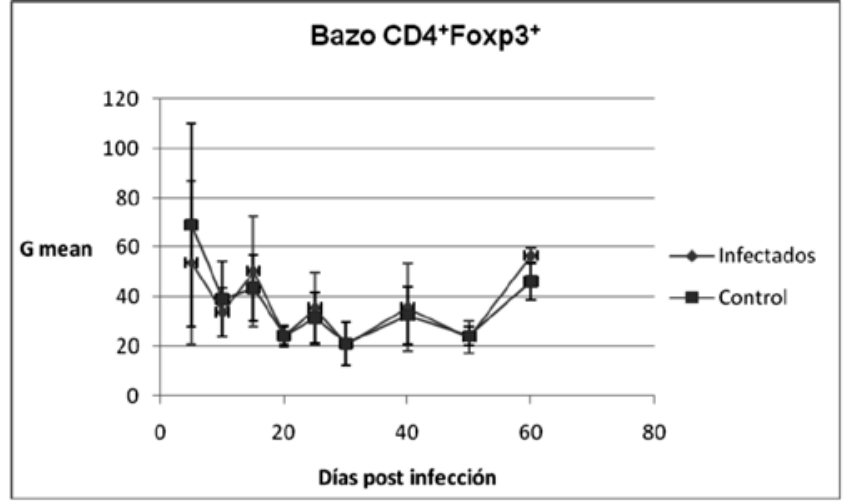

(a)

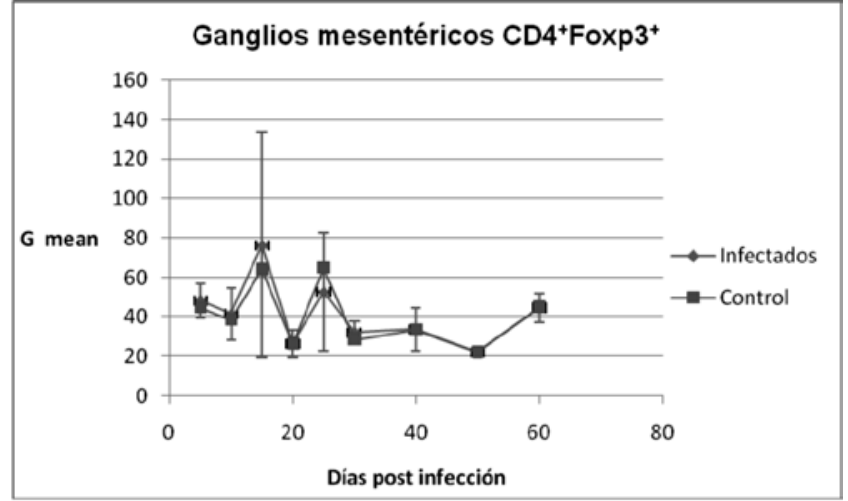

(b)

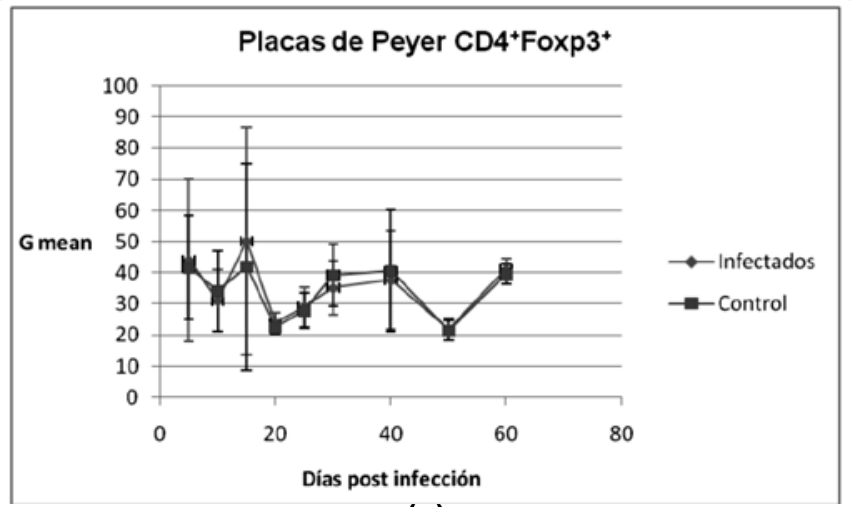

(c)

Figura 4. Intensidad media de fluorescencia de linfocitos CD4 ${ }^{+}$Foxp $3^{+}$ 


\section{Discusión}

El tracto gastrointestinal juega un papel de gran importancia en la definición de los antígenos que son tolerados y de los que provocarán una respuesta inmune. $\mathrm{Al}$ respecto, se ha involucrado a la población de células Treg $\mathrm{CD}^{+}$(Treg) en el fenómeno global de la regulación inmune en el intestino (14).

Inesperadamente, los esplenocitos y las células derivadas de los ganglios mesentéricos, tanto de los ratones infectados como de los no infectados, mostraron una tendencia a disminuir su proliferación ante ambos estímulos con el paso del tiempo. Las razones de esa disminución se desconocen, aún más en los ratones no infectados que normalmente presentan concentraciones de proliferación más elevados. Estos resultados contrastan con aquellos que mostraron inmunosupresión en esplenocitos a los días post-infección que aquí se ensayaron. Por otra parte, los niveles de proliferación de las células de placas de Peyer no variaron durante todo el experimento en ninguno de los grupos, lo cual sugiere que estas no fueron ni activadas ni suprimidas.

Asimismo, la identificación y cuantificación de las células Treg en ratones, requirió desarrollar una estrategia de marcaje combinado, utilizando tres diferentes moléculas: $\mathrm{CD}^{+}{ }^{+} \mathrm{CD} 25^{+}$y Foxp $3^{+}$. El marcaje con anticuerpos específicos conjugados con fluorocromos y analizados en el citofluorómetro, necesitó un considerable número de ensayos.

Sin embargo, los resultados no permiten adscribir un papel a las células Treg, dentro del fenómeno de supresión proliferativa en el modelo murino de amibiasis intestinal. Entre las causas que pueden involucrarse para explicar esta carencia, se puede mencionar la considerable variación experimental que impidió visualizar un fenómeno que debe ocurrir en niveles extremadamente bajos, por ejemplo, en algunas parasitosis se han observado cambios en la población de Treg entre 0,5 a 1\%, dependiendo del modelo experimental. Por ello, aunque es posible que las células Treg, no estén involucradas en el fenómeno de inmunosupresión observado en el modelo de amibiasis intestinal en ratones, los resultados presentados en el presente trabajo no permiten una conclusión definitiva, debido a la sincronicidad observada en los resultados de todos los tejidos (bazo, ganglios mesentéricos y placas de Peyer) obtenidos en ratones infectados y no infectados.

Los resultados obtenidos permiten sugerir otras estrategias para el análisis de población de Treg en la amibiasis intestinal, por ejemplo, estudiar el comportamiento de los ratones no infectados para determinar si las oscilaciones observadas se deben a que reaccionaron al pinchazo cuando se inyectó el PBS. Esto requiere de afinar las estrategias para definir la participación de las células Treg en estudios futuros.

\section{Referencias}

1. Walsh JA. Problems in recognition and diagnosis of amebiasis: estimation of the global magnitud of morbidity and mortality. Rev Infec Dis. 1986;8:228-238.

2. Ortiz-Ortiz L, Zamacona G, Sepúlveda B, Capín NR. Cell-mediated immunity in patients with amebic abscess of the liver. Clin Immunol Immunopathol. 1975;4:127-34.

3. Ghosh PK, Castellanos-Barba C, Ortiz-Ortiz L. Intestinal amebiasis: cyclic suppression of the immune response. Parasitol Res. 1995;81: 475-480.

4. GHOSH P., et al. Experimental Amebiasis: Immunohistochemical Study of Immune Cells Populations. J. Eukaryot. Microbiol. 2000;47:395-399.

5. Maloy, K. J., and Powrie, F. Regulatory T cells in the control of immune pathology. Nat. Immunol. 2001;.2:816-822.

6. Sakaguchi S, Sakaguchi N, Shimizu J, Yamazaki S, Sakihama T, Itoh M, Kuniyasu Y, Nomura T, Toda M, Takahashi T. Immunologic tolerance maintained by CD25+CD4+ regulatory T cells: their common role in controlling autoimmunity, tumor immunity, and transplantation tolerance. Immunol. Rev. 2001;182:18-32.

7. Gavin, M., and Rudensky, A. Control of immune homeostasis by naturally arising regulatory CD4+ T cells. Curr. Opin. Immunol. 2003;15:690-696.

8. Belkaid, Y., Blank, RB., Suffia, J.. Natural regulatory T cells and parasites: a common quest for host homeostasis. Immunol Rev Review. 2006; 212:287-300.

9. Hisaeda H, Hamano S, Mitoma-Obata C, Tetsutani K, Imai T, Waldmann $\mathrm{H}$, Himeno K, Yasutomo K. Resistance of regulatory $\mathrm{T}$ cells to glucocorticoid-viduced TNFR family-related protein (GITR) during Plasmodium yoelii infection. Eur J Immunol. 2005;35: 3516-3524.

10. Hesse M, Piccirillo CA, Belkaid Y, Prufer J, Mentink-Kane M, Leusink M, Cheever AW, Shevach EM, Wynn TA. The pathogenesis of schistosomiasis is controlled by cooperating IL-10-producing innate effector and regulatory T cells. J Immunol. 2004;172:3157-3166.

11. McKee, AS., Pearce, EJ. CD25+CD4+ cells contribute to Th2 polarization during helminth infection by suppressing Th1 response development. J Immunol. 2004;173:1224-1231.

12. Singh, KP., Gerard, HC., Hudson, AP., Reddy, TR, Boros, DL. Retroviral Foxp3 gene transfer ameliorates liver granuloma pathology in Schistosoma mansoni infected mice. Immunology. 2005;114:410-417.

13. JI, J., Masterson, J., Sun, J., Soong, L. CD $4^{+} \mathrm{CD} 25^{+}$regulatory T cells restrain pathogenic responses during Leishmania amazonensis infection. J Immunol. 2005;174:7147-7153.

14. Izcue A, Coombes JL, Powrie F. Regulatory $\mathrm{T}$ cells suppress systemic and mucosas immune activation to control intestinal inflammation. Immunological Reviews. 2006;212: 256-271. 